\title{
ESP Needs Analysis in Iran: The Case of University Students of Medicine
}

\author{
Nazli Azodi(corresponding author) \\ Department of Foreign Languages, Khorasgan (Isfahan) Branch \\ Islamic Azad University, Isfahan, Iran \\ E-mail: azodi_n@yahoo.com \\ Fatemeh Karimi \\ Department of Foreign Languages, Khorasgan (Isfahan) Branch \\ Islamic Azad University, Isfahan, Iran \\ E-mail: Fatinaz.karimi@yahoo.com
}

Received: June 4, 2017 Accepted: Oct. 26, $2017 \quad$ Published: November 1, 2017

doi:10.5296/jse.v7i4.11336 URL: https://doi.org/10.5296/jse.v7i4.11336

\begin{abstract}
It is believed that textbooks play the most vital role in the classrooms. A lot of class time is spent on using textbooks, thus choosing the appropriate one requires full considerations. A need analysis is a useful instrument to identify learner's needs as a prerequisite for effective course design including course books. To this end, this study aims to investigate the foreign language learning needs of Iranian students studying in faculties of medicine. The total number of 113 medicine students participated in the study to answer the prepared questionnaire whose results were compared with 125 other students from different universities with a different textbook. To obtain the desired result, qualitative descriptive analysis was used to evaluate the data. The results indicated that the new textbook fulfills the need of students for their reading and listening skills in general and it is also more satisfying to medicine students. This study could be helpful for medical departments of universities to select their ESP textbooks more carefully.
\end{abstract}

Keywords: ESP (English for Specific Purposes), medical textbook, need analysis 


\section{Introduction}

English is accepted globally as a lingua franca used for international communication (Coury, 2001; Crystal, 2003; Jenkins, 2004; Kurfürst, 2004; Schwarz, 2003; Seidlhofer, 2005; Yang, 2006). It is also accepted as an international language of communication in many fields, including medical science. English is essential for medical professionals as the world has become internationalized (Kang, 2004) and because almost all the medical information which medical students need to access is in English. As proposed by Kurfürst (2005), English is the most vital tool for medical students. For instance, they need to use English in their studies, which are for reading journals and textbooks when preparing for exams, or for discussion in class or at medical meetings. Furthermore, they have to learn to write patient charts, medication sheets, prescriptions and orders in English during their training and in their future medical careers. Hence, English for Medical Purposes (EMP) has become important.

No one can ignore the paramount function of textbooks in teaching English especially for specific purposes. They form the basis of any courses in this domain. As a matter of fact, English courses covered by textbooks should serve the courses in the best way as much as possible. McGrath (2006) states that "course books tend to dictate what is taught, in what order and, to some extent, how and what learners learn" (p. 171). He considers textbooks as the most important part of teaching, and evaluating textbooks as a task of great importance to the future success of programs. The decision of which textbook to use is an obligatory decision that will affect an entire generation of students, and new and reformed English textbooks can be more sufficient and useful.

The language of the most of the educational textbook notably in medicine or engineering in foreign language country such as in Iran is English. Therefore, the universities of these countries in their curriculums have the ESP course as an essential course. Although, nowadays the ESP course is one of the most important courses, and becomes more practical these days, this course is confined to just learning some vocabularies, language functions, grammatical points or translating texts. In this procedure, enough attention is not paid to the personal concerns and interests of the learners and their needs so, it often causes foreign language learners to have low motivation and as a result, their performances in using English in their future jobs decrease.

In Iran, textbooks serve as the basis for much of the language input learners receive and the language practice that takes place in the classroom (Riazi, 2003). In some situations, the textbook may function as a supplement to the teacher's instruction in the ESL teaching and learning process. For most teachers, textbooks provide the foundation for the content of lessons, the balance of the skills taught, as well as the kinds of language practice the students engage in during class activities. Actually, they shape the content and nature of teaching and learning (Riazi, 2003). Educators as well as learners spend a great deal of their preparation, class and time working with textbook materials because textbooks are primary sources that instructors and educators use throughout the world to guide them in teaching. Textbooks also provide a good framework for teachers to help them in teaching and supporting students in the process of learning. So, choosing the appropriate textbook for use in the science 
classroom is not an easy task (Sheldon, 1988). So, at the time of designing an ESP course, the first issue is paying attention to learners' needs and wants. Analyzing the specific needs of a particular learner group determines the 'what and how' of an ESP course (Hutchinson \& Waters, 1987). While there are numerous proposals for the evaluation of teaching materials, these proposals are much less common in the field of ESP. Considering this important issue is clear when Ansari and Babaii (2002), believe that teachers have the responsibility of evaluating textbooks, so the evaluation of teaching materials is an important part of a teacher's work.

There are some ways to evaluate textbooks such as needs analysis process to identify and evaluate needs, interrogating English teachers to find the text books' problems or even comparing new and previous textbooks and find the effect of new methods and materials. In addition, using checklists can play an important role in evaluating books especially in ESP courses in which the books are important in preparing students encounter the real context in their future workplace.

\subsection{Related Studies}

In Iranian context, the attitude of EFL teachers and learners of medical science was examined. To do this research 175 medical students and 25 EFL instructors were chosen from four medical universities (Zanjan University, Tehran Islamic-Azad University, Shahid-Beheshti University, and Tehran University). The instruments for data collection were a questionnaire and interview. The results reflected that there is not any difference between teachers and learners' attitudes about their ESP course book. Nevertheless, there are significance differences between their attitudes about their understanding of the six aspects of their book.

In another study in Iranian context done by Arani (2004), the language learning requirements of medical students at Kashan University of Medical Sciences were examined. Determining the attitude of learners about learning English as a school subject i.e. prior entering the university was the most important objective of this study. The research sample of this study was 45 medical students who registered in the first and second year of study. To collect the data, diverse kinds of questionnaires were given to the sample at the beginning, in the middle and at the end of the English for Medical Purposes (EMP) courses. The outcomes indicated that most of the subjects had positive attitudes towards both learning English and the English language teacher.

Baleghizadeh and Rahimi (2011) indicated that the systematic evaluation of textbooks is not often conducted and students' requirements and opinions concerning the materials developed for them are neglected in Iran. Likewise, Eslami-Rasekh (2010) pointed out that ESP textbooks developed for the students of engineering by the Ministry of Higher Education in Iran is not born out of any systematic needs analysis. In another study done by Amirian and Tavakoli (2009), they assessed and evaluated the elements of ESP textbooks for engineering students. They reported that ESP courses have been useful and successful in making background knowledge on terminology and reading proficiency of that specific field in the minds of future engineers. Finally, in an evaluation of the academic language requirements of computer science engineering students according to English for Specific Academic Purposes 
(ESAP) programs, Atai (2008) understood that written skills and language elements are of high value to learners. He found that the students had some problems with skills of reading, writing, speaking, and listening.

Finally, the most recent work which is done by Khorvash and Koosha (2015) and its results have been used in the present study investigated the needs and desires of medical sciences students in faculties of Medicine at the Isfahan University and Azad University of Yazd. A total number of 272 students studying medicine participated in the survey that 125 of them were currently taking the course(In-study group) and 147 students who had already completed the course (post-study group). The results showed that the majority of students in both groups expressed their dissatisfaction with their current textbooks, the content that were taught, the methodology that was used in teaching the course and the number of the students in the class.

\subsection{Statement of the problem}

Regarding the important role English plays in developing countries like Iran, where English is mainly used for academic purposes, EMP requires serious and careful considerations. Despite the government's high level of investment in EAP programs, there is very limited research (exceptions are: Atai, 2000; Eslami-Rasekh \& Valizadeh, 2004; Gooniband, 1988; Khajeie, 1993; Mazdayasna \& Tahririan, 2008) addressing the effectiveness of these programs from learners' perspectives.

In today's classrooms, textbooks are considered as instructional tools and guide. Teachers throughout the world use texts to guide their instruction. So, textbooks greatly influence the delivery of content. They identified textbooks as playing an important role in making supportive plans to classroom activities, by making content available, organizing it, and setting out learning tasks in a form designed to be appealing to students (Schmidt, McKnight, \& Raizen, 1997). Even though textbooks are important elements in most of EFL classes, there is no good attention to the process of textbook selection and evaluation. The reason for this maybe is the fact that in the age of communicative teaching, there is no attention to communicative methodologies in ESP classes in the field of English. Yet, regardless of how much focus is on using authentic materials, teachers usually do not have the time and the instructional support to collect and adapt all the necessary materials for their classes. Therefore, it is disappointing that researchers have not provided more guidance to enable teachers and administrators to make wiser decisions (Azizfar, Koosha, \&Lotfi, 2010).

This study therefore intended to examine the medical learner's attitudes, needs, and perceptions influenced by the content of their selected course book and also to make a comparison with the medical learner's attitudes, needs, and perceptions with a different course book in different universities. To achieve the purpose, the study proposes two main objectives of this research under the following questions:

1. What is the attitude of Iranians medical learners towards the content of their ESP course book? 
2. Are there any significant differences between the attitudes of Iranians medical learners with different books towards the ESP syllabi and their needs and desires?

\section{Method}

\subsection{Participants}

The aim of this study was to find out the needs and desires of medical students who are passing their English courses and to make a comparison with medical learners with different books. To this end, samples were randomly selected from the Department of Medicine at Najafabad Azad University with the total number of 113 medicine students, 36 males and 77 females, taking part in this study. These students were studying their English courses at the time of this research and they were all following the similar syllabus which includes the Medical Terminology book for medicine students written by Barbara Janson Cohen, sixth edition. They only differed in their instructors.

\subsection{Instruments}

In order to achieve the purpose of the research, the questionnaire of the needs analysis used in this study was a modified version of the one used by Mazdayasna and Tahririan, 2008. To ensure the appropriateness and comprehensibility of the items, the questionnaire was translated into Farsi. First, the participants filled out the personal information items such as name (which was optional), age, gender, their semester and whether they had passed their general English course. The questionnaire was divided into 3 sections. The first section which included 4 parts, each dedicated to four main skills (listening, speaking, reading and writing)consisted of 21 items (items 1-21) and these items were designed to explore the opinions of the students about their expressed needs for English language skills in their academic studies. Here the students were asked to express their opinions about each statement by marking the options on a six-point Likert scale ranging from 6 (to a very great extent) to 1 (not at all).

The items of the second and the third section (items 22 to 26 and 27 to 33) asked students' opinion concerning language demands, their language needs, their attitudes towards language instruction, the length of the course, and the content, syllabus, and methodology of the specialized English course. The second section used a multiple-choice format, while the third section followed the Likert scale. Since this study tried to evaluate and investigate the influence of the course textbooks on the students' needs and desires, the results of the questions 27 to 33 were not included in this study. The results have already been obtained and calculated by SPSS, hence can be used for later research.

\subsection{Data collection}

The data for the study were collected over the spring semester of 2014-2015 at Azad University of Najafabad. In order to obtain the required and desired results, the researcher distributed and collected the questionnaires in person. The Statistical Package for Social Sciences (SPSS) was used for statistical operations needed for data analysis. 


\section{Results and Discussion}

This part of the study includes a complete analysis of the results obtained from the data collection process about the research questions of the study. The statistics are shown completely in tables and the results obtained from the data are explained in details to prove the researcher's agreements or disagreements on research questions.

A needs analysis study was undertaken in medical sciences of Najafabad University with the aim of investigating the student's foreign language learning needs, wants and lacks thereof and evaluating their textbook. The assessment of learner's needs was performed through comparing the needs of students who currently enrolled in ESP courses with the results of another study performed the same assessment with a different textbook. Accordingly, the researcher obtained a full knowledge over the whole content to carefully evaluate the book.

As mentioned before, the first section of the questionnaire explores the opinions of the students about their expressed needs for English language skills in their academic studies. As it was intended to evaluate the opinions of the students about their textbook, their results were compared with the results of another study, Khorvash and Koosha (2015), used the same questionnaire for the medicine students of Isfahan University and Yazd Azad University who were studying a different textbook, English for Students of Medicine Samt publications by M.H. Tahririan and F. Mehrabi. The total numbers of the students at those universities were 125.

Table 1. Test Statistics of Listening Skill between C. Group \& S group

\begin{tabular}{lllllll}
\hline & Q1 & Q2 & Q3 & Q4 & Q5 & Q6 \\
\hline Mann-Whitney U & 6214.000 & 6878.000 & 6204.500 & 6367.000 & 6295.000 & 5744.500 \\
Wilcoxon W & 13840.000 & 14628.000 & 13954.500 & 13507.000 & 14170.000 & 13370.500 \\
Z & -1.608 & -.139 & -1.645 & -.650 & -1.730 & -2.533 \\
P-Value & .108 & .890 & .100 & .516 & .084 & .011 \\
\hline
\end{tabular}

As it is shown in the table (table 1), the students who were studying the Cohen book (C.group) quite agree that they need some improvements in their listening skills(Q1-Q6) and when they were compared to the students who were studying the Samt book (S.group) the P-value showed that there is a significant difference concerning their need to listening to students, colleagues and patients (Q6). 
Table 2. Test Statistics of Speaking Skill between C. group \& S. group

\begin{tabular}{lllllll}
\hline & Q7 & Q8 & Q9 & Q10 & Q11 & Q12 \\
\hline Mann-Whitney U & 6627.000 & 6295.000 & 5160.500 & 6630.000 & 6712.000 & 5903.500 \\
Wilcoxon W & 14502.000 & 13555.000 & 11376.500 & 14380.000 & 15623.000 & 14814.500 \\
Z & -1.009 & -1.117 & -2.442 & -.783 & -1.591 & -3.240 \\
P-Value & .313 & .264 & .015 & .434 & .112 & .001 \\
\hline
\end{tabular}

As far as the speaking skill is concerned (Q7-Q12), while the results indicated that the majority of the students "Agree" or "Quite agree" there is a need for improving their speaking skill, the C. group showed a significant difference in the need for asking and answering questions in the class (Q9) and for speaking to professors, students, and patients (Q12)(table 2).

Table 3. Test Statistics of Reading Skill between C. group \& S. group

\begin{tabular}{llllll}
\hline & Q13 & Q14 & Q15 & Q16 & Q17 \\
\hline Mann-Whitney U & 6984.000 & 7040.000 & 7059.500 & 6805.500 & 6790.000 \\
Wilcoxon W & 14859.000 & 13481.000 & 13500.500 & 13133.500 & 13231.000 \\
Z & -.241 & -.060 & -0.07 & -.415 & -.605 \\
P-Value & .810 & .952 & .994 & .678 & .545 \\
\hline
\end{tabular}

Considering the reading skill (Q13-Q17), it can be observed that even though S. group felt more need for improving their reading skill but there is a marginal reduction in the need for improving the reading skill in C. group. But still the difference is not significant (table 3).

Table 4. Test Statistics of Writing Skill between C. group \& S. group

\begin{tabular}{lllll}
\hline & Q18 & Q19 & Q20 & Q21 \\
\hline Mann-Whitney U & 6154.500 & 6278.500 & 6625.000 & 6865.000 \\
Wilcoxon W & 14029.500 & 14924.500 & 14375.000 & 14491.000 \\
Z & -1.800 & -2.155 & -.778 & -.169 \\
P-Value & .072 & .031 & .436 & .866 \\
\hline
\end{tabular}

The last skill to be observed is the writing skill (Q18-Q21) which showed that the majority of the students in C. group "Agree" or "Quite agree" for the need to improve their listening skill (table 4). But the only significant difference between the groups is for the need to improve 
taking notes from their textbooks (Q19). On the other hand, questions 22 to 26 aimed to find out about the medical students' degree of satisfaction regarding the number of the students, the materials and the way of presenting them. The statistics showed that S. group needed more improvement in the number of students in the class which can be excluded from this study analysis since it is not related to the textbook. While the majority of the students in the C. group "Agree" or "Quite agree" in their satisfaction of the topics provided in their textbook, the way of presenting them in the class, the textbook itself, and its content, the P-Value showed a significant difference among two groups (table 5).

Table 5. Test Statistics of the Students' Satisfaction

\begin{tabular}{llllll}
\hline & Q22 & Q23 & Q24 & Q25 & Q26 \\
\hline Mann-Whitney U & 4947.000 & 2275.500 & 4196.500 & 1792.500 & 2094.000 \\
Wilcoxon W & 11052.000 & 9535.500 & 11456.500 & 9052.500 & 9844.000 \\
Z & -3.384 & -88.829 & -4.895 & -9.752 & -9.359 \\
P-Value & .001 & .000 & .000 & .000 & .000 \\
\hline
\end{tabular}

After investigating the skills and the amount of satisfaction among the two groups individually for each question in all skills, there is a need to have an overall look on the illustrated categories in order to compare the two groups precisely (table 6). 


\section{Macrothink}

Table 6. The Mean Scores of 2 Groups in 4 Skills \& Satisfaction Level

\begin{tabular}{llllll}
\hline & & $\mathrm{N}$ & Mean & Std. Deviation & P-Value \\
\hline Listening & Cohen book & 113 & 86.01 & 18.720 & .066 \\
Skill & & & & &
\end{tabular}

\begin{tabular}{llllll} 
& Samt Book & 125 & 80.91 & 23.246 & \\
& Total & 238 & 83.33 & 21.327 & \\
\hline Speaking & Cohen book & 113 & 87.11 & 18.580 & .005 \\
Skill & & & & &
\end{tabular}

\begin{tabular}{llllll} 
& Samt Book & 133 & 79.25 & 23.770 & \\
& Total & 246 & 82.86 & 21.854 & \\
\hline Reading & Cohen book & 113 & 90.28 & 15.190 & .870 \\
Skill & & & & &
\end{tabular}

\begin{tabular}{llllll} 
& Samt Book & 125 & 89.92 & 18.095 & \\
& Total & 238 & 90.09 & 16.745 & \\
\hline Writing & Cohen book & 113 & 77.16 & 22.438 & .033 \\
Skill & & & & &
\end{tabular}

\begin{tabular}{llllll} 
& Samt Book & 131 & 70.15 & 27.907 & \\
& Total & 244 & 73.39 & 25.709 & \\
\hline Satisfaction & Cohen book & 110 & 68.77 & 21.896 & .000 \\
Level & & & & & \\
& & & & & \\
& Samt Book & 124 & 39.44 & 30.962 & \\
& Total & 234 & 53.23 & 30.752 & \\
\hline
\end{tabular}

According to the table 6, the independent T-test indicated the differences among the two groups (S. group \& C. group) in the need of the students for improving specific features in their English courses considering the main four skills and their satisfaction level. It is clear that while the C. group asked for the need for improvement more than the S. group, these differences are significant in speaking, writing, and satisfaction level (P-Value $<0.05)$. But there are no significant differences among the two groups in their reading and listening skills. 
The most important part to be considered here is the level of satisfaction in C. group from their textbook which is significantly more than S. group.

\section{Conclusion}

This study aimed at qualitatively evaluating the textbooks by using a questionnaire. As it mentioned before, to draw conclusions based on the students' perceptions is an essential step in the learner-centered approach to course design (Nunan, 1988), which recently has become the most used approach among researchers and curriculum developers (Tudor, 1996). This study therefore intended to examine the medical learners' attitudes, needs, and perceptions influenced by the content of their selected course book and also to make a comparison with the learners' attitudes, needs, and perceptions with different course book in different universities.

The present study investigated the needs of the two different university students with different textbooks. The students of Najafabad Azad University were studying the 'Medical Terminology' by Barbara Janson Cohen (sixth edition). This course book is one of the newest books which have been selected for medical students. It consists of useful and practical terminologies with the aim of teaching the students to try to find the roots of the words and they are followed by various types of exercises. It also has some articles and short passages for improving reading for comprehension skill among learners. This study compared this course book with the book taught in Isfahan University and Yazd Azad University. Their course book is the one which is under the supervision of the Iranian Center for Studying and Compiling University Books (SAMT).

In sum, the results indicated that those students who are studying the newer book with original texts and vocabularies need less improvement in their reading and listening skills. In general, they showed a higher and more significant level of satisfaction toward their course book. It can be inferred that the university students of medicine in Iran might still need some changes in their textbooks to improve their productive skills which are speaking and writing. Even though from the students' view point it can be understood that they are more satisfied with the content and the topics of the more up-to-date book, but still there are more to be done in this regard.

We have stressed that ESP textbooks can be useful whenever we make a flexible use of them (Singh, 1983; Cunnings worth, 1984; Grant, 1987; Ellis \& Johnson 1994; Donna, 2000). Thus, modifying some parts of the book can be beneficial to cover all the course goals and encourage students to improve their language knowledge and skills. The findings of the present study bear significant implications for materials developers and teachers specifically in applying appropriate supplementary materials to compensate for those areas which need modifications.

Finally, conducting needs analysis helps book writers to improve their works and also develop and write the materials that are according to the learners' needs. Instructors can also be aware of the needs of the learners and pay enough attention to their requirements. It is also of interest to include more exercises about other language skills except for reading and 
listening skills. Medical students need to get familiar with the requirements of their future job in real life situations to have professional progress.

\section{References}

Azarnoosh, M., \& Ganji, M. (2014). ESP book evaluation: The case of management course book. International Journal of Secondary Education. https://doi.org/10.11648/j.ijsedu.20140204.11

Hwang, Y., \& Liu, S. (2010). A study of medical student's linguistic needs in Taiwan. The Asian ESP Journal.

Khorvash, F., \& Koosha, M. (2015). An exploratory study of ESP needs of Iranian students of medicine. International Journal of Current Life Sciences.

Mazdayasna, G., \& Tahririan, M.H. (2008). Developing a profile of the ESP needs of Iranian students: The case of students of nursing and midwifery. Journal of English for Academic Purposes. https://doi.org/10.1016/j.jeap.2008.10.008

Long, M. H. (2005). Second language needs analysis. Cambridge Applied Linguistics. https://doi.org/10.1017/CBO9780511667299

Salehi, H., Khadivar, Z., \& Mehrabi, M. (2015). Evaluation of an ESP medical textbook: Instructors and learners' perceptions in focus. Canadian Center of Science and Education. https://doi.org/10.5539/ies.v8n7p97

Soleimani, H., \& Shafie Khah, N. (2014). Are ESP textbooks satisfying students?: A case in Iran. International Journal of Language Learning and Applied Linguistics World (IJLLALW). 